\title{
On-pump versus off-pump coronary artery bypass grafting
}

Timothy J. Gardner, MD

See related article on page e2.
From the Department of Cardiothoracic Surgery, Christiana Hospital, Christiana Health Care System, Newark, Del.

Received for publication Sept 12, 2006; accepted for publication Sept 20, 2006.

Address for reprints: Timothy J. Gardner, MD, Department of Cardiothoracic Surgery, Christiana Hospital, Christiana Health Care System, Management Suite 1218, PO Box 6001, Newark, DE 19718 (E-mail:tgardner@ christianacare.org;

1thomas@christianacare.org).

J Thorac Cardiovasc Surg 2007;133:1

$0022-5223 / \$ 32.00$

Copyright $@ 2007$ by The American Association for Thoracic Surgery

doi:10.1016/j.jtcvs.2006.09.006
$\mathrm{O}$ $\mathrm{n}$ the basis of a meta-analysis of five published reports that compare results of off-pump (OPCAB) versus on-pump coronary bypass graft (CABG) procedures, Takagi and his coauthors ${ }^{1}$ claim that $\mathrm{OPCAB}$ resulted in a significant increase in overall graft occlusion. Their conclusion is based on follow-up angiographic studies done between 3 and 12 months in these randomized patients. Their analyses of the data from these five studies seem to establish that vein graft patency at 3 to 12 months after surgery is reduced with OPCAB. On this basis, the authors ask: "Dare we perform OPCAB rather than CABG to merely improve ... selected clinical and resource outcomes?"

The five studies that comprise this meta-analysis contain only 1098 total patients. As few as $64 \%$ of the patients in 1 study actually had postoperative studies of graft status. Internal thoracic artery graft patency was not different between CABG and OPCAB surgery in any of the five reports, and the late patency of vein grafts was not statistically different in two of the five reports. These facts, as well as common sense, should mitigate the sense of certainty created by the authors' reliance on statistical analysis of complex data, which has prompted them to conclude that $\mathrm{OPCAB}$ risks effective revascularization.

Experienced cardiac surgeons recognize that for the occasional patient, such as one with severe aortic atherosclerosis, off-pump grafting is safer. Most experienced surgeons also recognize that some patients do not tolerate the temporary interruption of flow to a coronary artery that is being grafted while the heart is beating. They know that some other patients, especially those with ventricular enlargement or valve incompetence who may not tolerate the positioning maneuvers required to construct all of the desired coronary grafts, are more safely grafted on bypass. Also, available published and reported data suggest that, in general, fewer grafts are done off-pump compared with historical reports of conventional CABG procedures.

Beyond these facts, and in the absence of a large, multicenter, multi-operator, randomized study of OPCAB versus on-pump CABG surgery in comparable patients, the choice of which technique to use should remain the surgeon's option. A sage senior cardiac surgeon was asked by a friend to reveal how he would decide whether to choose conventional on-pump versus off-pump bypass grafting if he became a candidate for CABG. The critical choice for him, he said, was not between on- versus off-pump surgery; it was to choose the most skilled surgeon and then to defer to that surgeon's choice of technique.

Here is a final reflection on the role of OPCAB. Were it not for our young colleagues who have championed $\mathrm{OPCAB}$, the option of successfully using this approach when preferable to conventional CABG surgery would not exist today. Just like the situation surrounding the early adoption of laparoscopic cholecystectomy, it has been our "daring" colleagues, often younger associates, who have developed and refined the techniques that allow us successfully to avoid the pump today when clearly necessary.

\section{Reference}

1. Takagi H, Tanabashi T, Kawai N, Kato T, Umemoto T. Off-pump coronary artery bypass sacrifices graft patency: Meta-analysis of randomized trials. J Thorac Cardiovasc Surg. 2007:133:e2-3. 